\title{
Functional Textile Preferences of Elderly People
}

\author{
Sema Palamutcu \\ Imren Goren \\ Pamukkale University, Engineering Faculty, Textile Engineering Department, Denizli -Turkey \\ spalamut@pau.edu.tr
}

\section{Doi:10.5901/mjss.2015.v6n2s5p279}

\section{Abstract}

Aging is an inevitable stage of lifetime bringing along physical and emotional deterioration. Rate of aging population in the world has been constantly rising with the contribution of technological improvements on life quality, and medical services. Depending on the unavoidable physical and emotional changes of aging human body, clothing preferences and needs become different then needs of other textile and clothing consumer groups. Textile and clothing products are one of the basic needs of human kind. Sufficient and appropriate clothing is especially important for life quality improvement at elderly stage of human life. New generation functional and smart textile and clothing products bring new opportunities to improve life quality of elderly people with such wide range products of mobility support clothing, medical help, hygiene, and health monitoring textile and clothing products. This survey based research work is aimed to search the awareness level and priority of society about the functional and smart textile products for elderly people. It has been found that gender difference has significant influence on preference level of functional textile products, where women has higher interest then men about functional textiles. It can also be stated that comfort properties are primarily preferred preferences comparing to the fashion and functionality properties of textile products.

Keywords: Elderly people, functional textiles, smart textiles

\section{Introduction and Literature Review}

Average living time of human being is steadily increasing. As result of the longer life time the number of people in the aging $^{1}$ group is also increasing. Currently 8,3\% of World population is over 65 years old and it is estimated that this rate will be about $16 \%$ in 2050 (Url 1).

Consumer based needs of aging population is different than other consumer groups. There are several studies concerning their behaviors and special needs of elder consumers. In the study of Richards (1981) clothing preferences and problems of elderly female consumers are researched. Jackson (1992) had studied spending patterns of elderly consumers (age 60 and above) on personal apparel. Shim (1993) had researched differences in satisfaction with the fit of apparel purchased through catalogs and catalog attributes among three groups (petite, medium, and tall) of women 55 years and older. Goldsberry (1996-a, 1996-) had focused on women 55 years and older about their current body measurements and overall satisfaction and dissatisfaction with the fit of ready-to-wear clothing. Vural (2008) had studied body size standardization in terms of underwear production of women over 60 years old. In the report of Meinander (2002) problems that can occur concerning clothing and textiles for disabled and elderly people are identified and suggestion has been offered to solve their problems where possible. Civitci (2004) has focused on the ergonomic garment design for elderly Turkish men that she has determined elderly men's demands, needs and problems in regard to clothing and to design an ergonomic garment in the light of the knowledge. Joung (2006) has questioned the factors of dress affecting self-esteem in older females. It has implemented that in order to maintain self-esteem in old age, individuals should be encouraged to participate in social activities and appearance management activities; the fashion and personal care industry should have an awareness of older female consumers' needs and develop and provide agerelated products and services. Pisut (2007) has studied fit preferences of female consumers in the USA. Mona, Mak Man Nga (2011) has completed a thesis, namely "Study and design of elderly aesthetic apparel", in Bachelor of Arts (Honors) In Fashion \& Textiles program in Institute of Textiles \& Clothing the Hong Kong Polytechnic University. Her aim was to

${ }^{1}$ At the moment, there is no United Nations standard numerical criterion, but the UN agreed cutoff is $60+$ years to refer to the older population (Url 2). 
understand the elderly clothing in general, including wearing requirements, wearing difficulties, clothing preferences and design an aesthetic-oriented elderly apparel which helps to improve the design, materials usage and address potential problem; and find out the real situation and demands toward garments of elderly in Hong Kong. Chattaraman (2013) has focused on the age, body size, body image, and fit preferences of male consumers in their statistically study. They have offered important implications and created actionable market information on fit strategy for male consumer segments. Twiggy (2014) had addressed debates around the changing nature of old age, using UK data on spending on dress and related aspects of appearance by older women to explore the potential role of consumption in the reconstitution of aged identities.

Textile and clothing products are one inevitable consumer product for human being. Beside the basic use purposes of covering and protection; textile and clothing products had started to have some more additional features. Classical form of textile and clothing products are in significant progress stage that moves forward becoming technical, functional, and smart textile products. The expertise gained from many years of research is being more intimately married with expertise from other engineering, scientific and design sectors, giving rise to a new breed of functional and smart technologies (Tang 2005). The term "smart" in textile and clothing products includes meaning of functionality and has been used to refer to materials that can sense and respond in a controlled or predicted manner to environmental stimuli, which can be delivered in mechanical, thermal, chemical, magnetic or other forms (Tao, 2001). The difference between functional and smart textile products can be defined as responding ability presence of the product. Functional textile products are those products that they may only provide permanent or temporary additional features of antimicrobial, fire retarding, stain resistive, antistatic, quick drying, odor resistive, etc. properties; where smart textile products provide direct and indirect responses.

Interest of functional and smart textile and clothing product has lately grown exponentially. Promising sub divisions of functional and smart textiles are military textiles, geotextiles, medical textiles, sport and leisure textiles, wearable electronics, and transportation textiles. Special products designed to improve and help elderly people is also one rising sub sector of functional and smart textiles. This product group is an intersection of other current functional and smart textile product groups which are medical textile, wearable - electronic textiles, sport textiles, and protective textiles. Market penetration and commercialization of such special products are rising as result of gradual reduction of component costs, rising consumer interest and improving technologies.

Market share of those special textile products for elderly people is also growing as result of increasing share of elderly people in the society. Another main driving force behind the market growth is consumer purchase power in the developed countries. Especially baby boomer generation ${ }^{2}$ has become retired with their cash build up and pensions that is easily spendable for their own health care and any other expenses to improve their life quality and help them to live independent and longer.

Survey suggests that aging is associated with physical and emotional changes which can be repaired, accomplished and cared using some external products. Gender, age group, and education level are selected as dependent variables questioning preferences and awareness level about functional and smart textile products for elder people.

\section{Objectives of the Study}

Presented study is aimed searching the following objectives:

1. Exploring the attitudes of the society about functional textile and clothing products regarding the gender, age and education differences.

2. Exploring the significance of product properties and consumer performance criteria expectations among society regarding the gender, age and education differences.

3. Comparing the general expectations and views of participants based on their own knowledge about elderly functional and smart textile and clothing products.

\section{Method of the Research}

Questionnaire form has built up in three parts of demographic data, five levels Likert Scale measurement of textile product property priorities, and five level Likert Scale measurements of elderly textile products. Participants are answered 39 questions of three parts in total, using face to face survey method. In total 212 valid participants from Pamukkale

2 The Baby Boomers are defined as those born between 1945 and 1964 in USA and in Europe. 
University-Denizli/Turkey, and Retired Teacher House in Muğla/Turkey is responded to the questions. Five level Likert Scale data and its weight values are given in Table 1.

Table 1: Five level Likert Scale and weights of responses

\begin{tabular}{lll}
\hline \multicolumn{1}{c}{ 1. Responses } & 2. Weights \\
\hline 3. certainly not agree & 4. & 1 \\
5. not agree & 6. & 2 \\
7. uncertain & 8.3 \\
9. agree & 10.4 \\
11. Strongly agree & 12.5 \\
\hline
\end{tabular}

Questionnaire has four main part, which are part l: demographic data of gender, age, and education level; part II: 20 questions about general awareness level of functional and smart textile products; part III: 9 questions of general expectations about functional and smart textile; and part IV: 10 questions about awareness and interest to functional and smart textile products designed specifically for elderly people. Likert scale based answers of the questions are then recorded, and used for the estimation of median, standard deviation, and significance (at \%95 confidence intervals) values.

\section{Findings and Results}

Demographic data of the participants are presented in Figure 15, for total of 212 participants. Rate of female participants in total is 55\%; rate of participants aged between $18-25$ is $38 \%, 25-40$ is $8 \%, 40-60$ is $37 \%$, and $60+$ is $17 \%$; and education level of participant rates are elementary school is $7 \%$, high school is $11 \%$ and university graduates is $82 \%$.

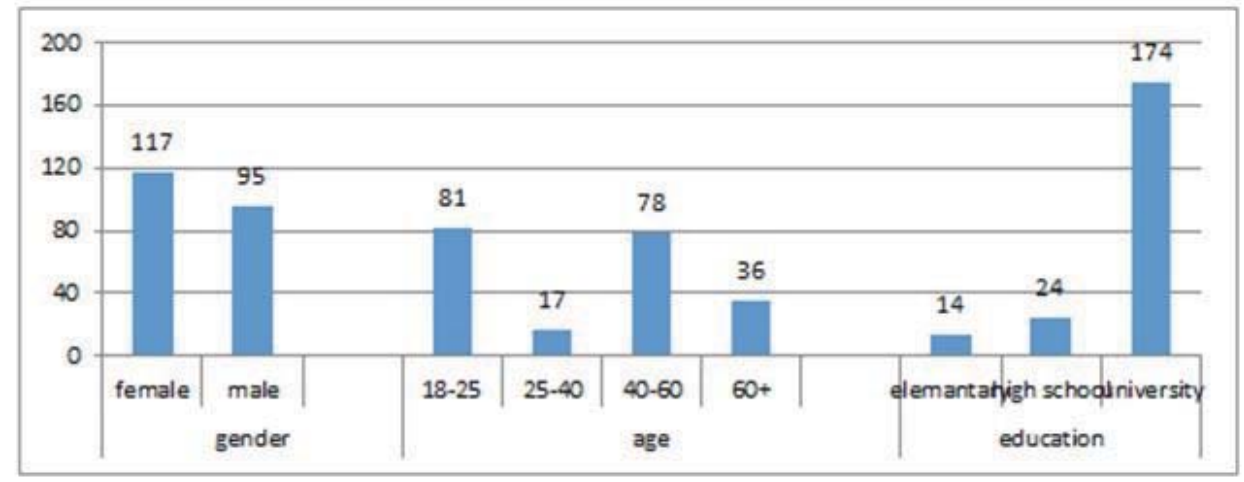

Figure 1: Demographic data of participants

Responses of participants to the questions in Part II of the survey Part II are given in Table 2. There are 20 statements presented to the participants, in order to control and compare the general awareness level about functional and smart textile and clothing products. The participants are required to choose their agreement levels of each statement in Likert Scale. 11 statements out of 20 is found non significantly different among the participant responses, where they are defined as having homogenous variances of all participants. Statements that are determined as having homogeneous variance are "Dirt and stain repellency in T \& C is important for me", "Size stability in wool T \& C is important for me", "Shiny surfaced fabric use in T \& C is important for me", "Anti-static ability in T \& C is important for me", "Wound healing ability in T \& C is important for me", "Heat storage and management ability in T \& C is important for me", "Cooling in T \& $C$ is important for me", "Head ache curing ability in head covering products is important for me", "Odor releasing ability in T \& C is important for me", "High elasticity in in T \& C is important for me", "Quick drying in T \& C is important for me".

In general evaluation of the participant responses, it is seen that female participants and age group of 40-60 are more likely to have interest about functional and smart textiles comparing to the male and other age group of participants. 
Table 2: Questions, medians, standard deviations, F and significance values of Part II

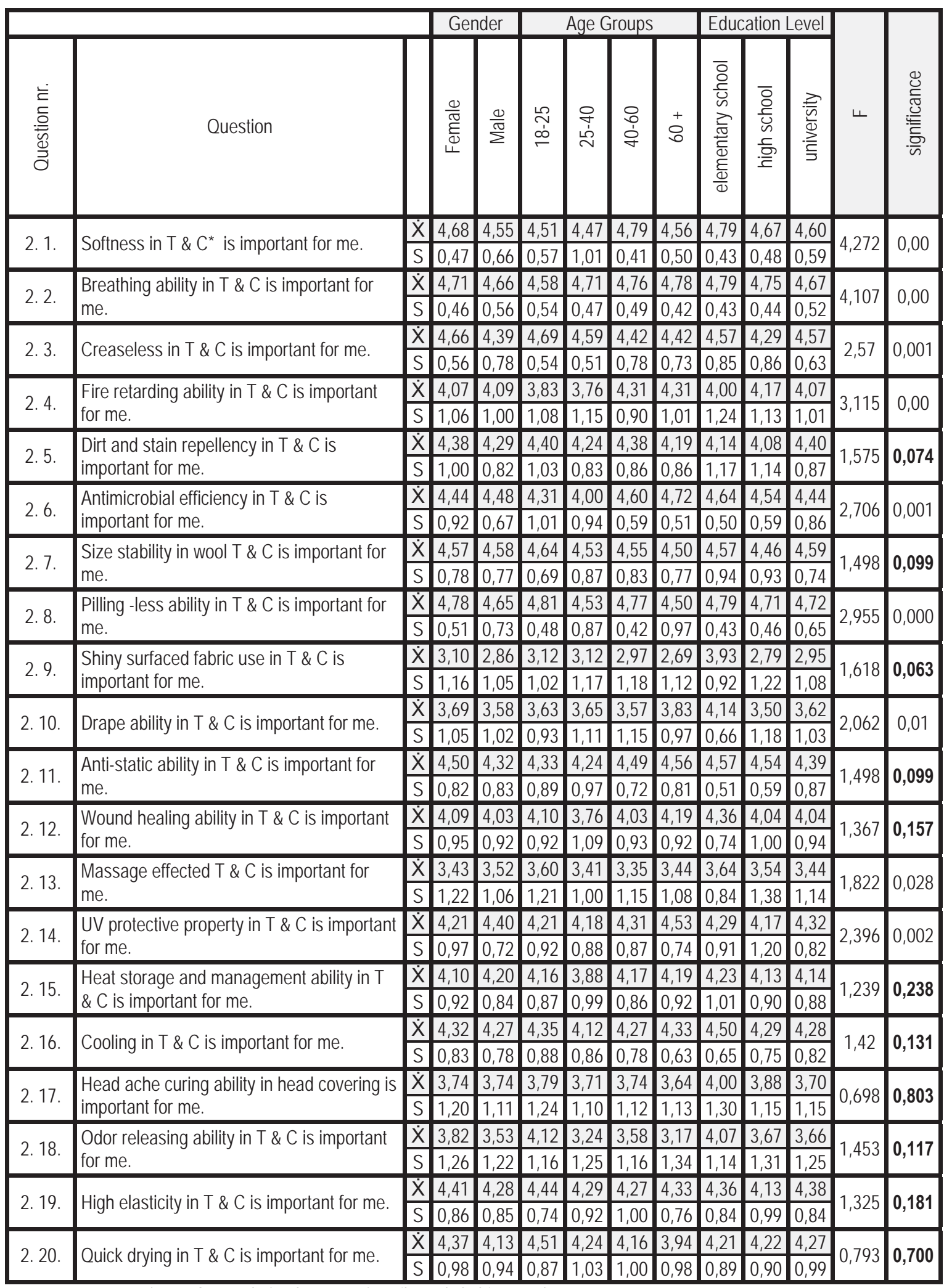

*: T \& C stands for the term of textile and clothing product 
Responses of participants to the questions in Part III of the survey are given in Table 3 . There are 9 statements presented to the participants, in order to control and compare the general expectations and performance criteria knowledge of functional and smart textile and clothing products. 1 statements out of 10 is found non significantly different among the participant responses, where they are defined as having homogenous variances of all participants. Statement that are determined as having homogeneous variance is "Functionality in $T \& C^{*}$ is important for me", which is clearly understand among participants of the survey. The other statements are determined as non-homogeneously variance statements, where understanding and knowledge about them are not homogeny among participants.

In general evaluation of the participant responses, it is seen that female participants are more focused about fashion, aesthetic and functionality, where male participants are more focused on price, quality, and long lasting property of products.

Table 3: Questions, medians, standard deviations, F and significance values of Part III

\begin{tabular}{|c|c|c|c|c|c|c|c|c|c|c|c|c|c|}
\hline & & & \multicolumn{2}{|c|}{ Gender } & \multicolumn{4}{|c|}{ Age Groups } & \multicolumn{3}{|c|}{ Education Level } & \multirow[b]{2}{*}{ ४ } & \multirow[b]{2}{*}{ 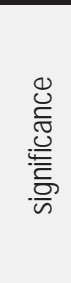 } \\
\hline 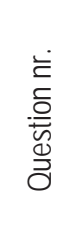 & Question & & $\begin{array}{l}\frac{\mathscr{U}}{\widetilde{\widetilde{U}}} \\
\bar{\varpi} \\
\amalg\end{array}$ & $\frac{0}{\frac{0}{\pi}}$ & $\underset{\sim}{\stackrel{\omega}{o}}$ & 古 & $\begin{array}{l}\text { ర্ } \\
\text { 字 }\end{array}$ & $\stackrel{+}{8}$ & 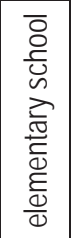 & $\begin{array}{l}\overline{\mathrm{o}} \\
\text { 든 } \\
\text { 을 } \\
\text { ․ㅡㄹ }\end{array}$ & 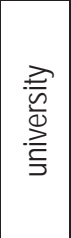 & & \\
\hline \multirow{2}{*}{ 3. 1 . } & \multirow{2}{*}{ Fashion in $\mathrm{T} \& \mathrm{C}^{\star}$ is important for me. } & & 3,82 & 3,44 & 3,89 & 2,94 & 3,55 & 3,67 & 3,71 & 3,63 & 3,65 & \multirow{2}{*}{1,907} & \multirow{2}{*}{0,019} \\
\hline & & $\mathrm{s}$ & 1,13 & 1,26 & 1,13 & 1,56 & 1,16 & 1,17 & 1,27 & 1,28 & 1,20 & & \\
\hline \multirow{2}{*}{ 3. 2 . } & \multirow{2}{*}{$\begin{array}{l}\text { Strength, long life and steadiness in T \& } \\
C^{*} \text { is important for me. }\end{array}$} & $\dot{x}$ & 4,59 & 4,49 & 4,57 & 4,41 & 4,60 & 4,47 & 4,57 & 4,46 & 4,56 & \multirow{2}{*}{2,569} & \multirow{2}{*}{0,001} \\
\hline & & $S$ & 0,63 & 0,67 & 0,67 & 1,00 & 0,52 & 0,65 & 0,51 & 0,78 & 0,64 & & \\
\hline \multirow{2}{*}{ 3. 3.} & \multirow{2}{*}{$\begin{array}{l}\text { Wellness and good feeling in T \& } C^{*} \text { is } \\
\text { important for me. }\end{array}$} & $\dot{x}$ & 4,67 & 4,49 & 4,75 & 4,24 & 4,56 & 4,44 & 4,57 & 4,54 & 4,60 & \multirow{2}{*}{3,799} & \multirow{2}{*}{0,00} \\
\hline & & $\mathrm{s}$ & 0,56 & 0,67 & 0,43 & 0,83 & 0,64 & 0,69 & 0,51 & 0,83 & 0,59 & & \\
\hline \multirow{2}{*}{ 3. 4.} & \multirow{2}{*}{$\begin{array}{l}\text { Material quality in T \& C* is important for } \\
\text { me. }\end{array}$} & $\dot{x}$ & 4,40 & 4,57 & 4,46 & 4,41 & 4,49 & 4,53 & 4,08 & 4,58 & 4,49 & \multirow{2}{*}{2,074} & \multirow{2}{*}{0,009} \\
\hline & & $S$ & 0,79 & 0,63 & 0,79 & 0,71 & 0,74 & 0,56 & 1,19 & 0,65 & 0,69 & & \\
\hline \multirow{2}{*}{ 3. 5.} & \multirow{2}{*}{$\begin{array}{l}\text { Ratio between quality and price in } \mathrm{T} \& \mathrm{C}^{\star} \\
\text { is important for me. }\end{array}$} & $\dot{x}$ & 4,38 & 4,44 & 4,11 & 4,29 & 4,64 & 4,61 & 4,71 & 4,71 & 4,34 & \multirow{2}{*}{2,885} & \multirow{2}{*}{0,00} \\
\hline & & $S$ & 0,92 & 0,78 & 1,10 & 0,77 & 0,56 & 0,60 & 0,47 & 0,46 & 0,91 & & \\
\hline \multirow{2}{*}{ 3. 6 . } & \multirow{2}{*}{$\begin{array}{l}\text { Easy cleaning in } T \& C^{*} \text { is important for } \\
\text { me. }\end{array}$} & $\dot{x}$ & 4,68 & 4,54 & 4,70 & 4,59 & 4,56 & 4,53 & 4,71 & 4,58 & 4,61 & \multirow{2}{*}{2,183} & \multirow{2}{*}{0,006} \\
\hline & & $S$ & 0,51 & 0,56 & 0,51 & 0,51 & 0,55 & 0,56 & 0,47 & 0,50 & 0,55 & & \\
\hline \multirow{2}{*}{ 3. 7.} & \multirow{2}{*}{ Price in $T \& C^{*}$ is important for me. } & $\dot{\bar{x}}$ & 4,40 & 4,52 & 4,35 & 4,71 & 4,48 & 4,50 & 4,71 & 4,63 & 4,40 & \multirow{2}{*}{1,977} & 0014 \\
\hline & & $\mathrm{S}$ & 0,91 & 0,62 & 0,88 & 0,47 & 0,77 & 0,74 & 0,47 & 0,58 & 0,83 & & 1,014 \\
\hline & lity in $T \& C^{\star}$ is important for & $\dot{x}$ & 4,44 & 4,27 & 4,36 & 4,18 & 4,39 & 4,39 & 4,29 & 4,35 & 4,37 & 1586 & 0.071 \\
\hline & & $\mathrm{s}$ & 0,72 & 0,75 & 0,76 & 0,81 & 0,75 & 0,64 & 0,91 & 0,88 & 0,71 & 1,000 & \\
\hline & ovement in $T \& C^{*}$ is & $\dot{x}$ & 4,84 & 4,73 & 4,84 & 4,76 & 4,76 & 4,75 & 4,79 & 4,83 & 4,78 & & \\
\hline & & $\mathrm{S}$ & 0,39 & 0,45 & 0,37 & 0,56 & 0,43 & 0,44 & 0,43 & 0,48 & 0,41 & 0,410 & \\
\hline
\end{tabular}

*: T \& C stands for the term of textile and clothing product

Responses of participants to the questions in Part III of the survey are given in Table 4. There are 10 statements presented to the participants, in order to control and compare the general awareness of elderly textile and clothing products. 4 statements out of 10 is found non-significantly different among the participant responses, where they are defined as having homogenous variances of all participants. Statements that are determined as having homogeneous variance are "Direction mentioning vibration shoes are important for elder people", "GPS purposed T\&C products are important for elder people", "Body vital signal watching T\&C products are important for elder people", and "Skin caring, cosmetic T\&C products are important for elder people", which are clearly understand among participants of the survey. The other statements are determined as non-homogeneously variance statements, where understanding and knowledge about them are not homogeny among participants. 
Table 4: Questions, medians, standard deviations, $F$ and significance values of Part IV

\begin{tabular}{|c|c|c|c|c|c|c|c|c|c|c|c|c|c|}
\hline & & & $\mathrm{Ge}$ & & & Age & roups & & & cation & evel & & \\
\hline 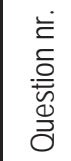 & question & & 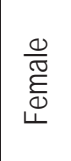 & $\frac{\frac{\infty}{\pi}}{\sum \frac{\pi}{\Sigma}}$ & $\begin{array}{l}\stackrel{\sim}{\sim} \\
\stackrel{\sigma}{\sim}\end{array}$ & $\begin{array}{l}\text { P } \\
\stackrel{\text { ஸे }}{N}\end{array}$ & $\begin{array}{l}\text { ọ } \\
\text { o }\end{array}$ & $\begin{array}{l}+ \\
8\end{array}$ & 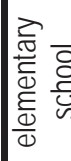 & 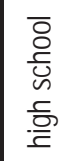 & 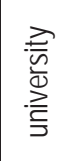 & $\sqcup$ & 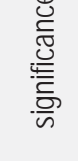 \\
\hline & & & 4,74 & 4,58 & 4,74 & 4,71 & 4,62 & 4,61 & 4,50 & 4,83 & 4,66 & & \\
\hline 4. 1 . & & & $\begin{array}{ll}0,63 \\
\end{array}$ & $0,0,59$ & 0,52 & 0,59 & 0,71 & 0,64 & 0,85 & \begin{tabular}{|l|}
0,38 \\
\end{tabular} & \begin{tabular}{l|l}
0,62 \\
\end{tabular} & 1,96 & \\
\hline & Odor & & 4,74 & 4,46 & 4,80 & 4,65 & 4,51 & 4,39 & 4,43 & 4,71 & 4,61 & & \\
\hline 4. 2 . & & & 0,61 & 0,78 & $\overline{0,43}$ & 0,86 & 0,72 & 0,96 & 0,51 & 0,69 & 0,72 & 448 & \\
\hline & Brea & $\dot{\mathrm{X}}$ & 4,75 & 4,62 & 4,74 & 4,65 & 4,68 & 4,64 & 4,57 & 4,75 & 4,70 & & \\
\hline 4. 3 . & & $S$ & 0,51 & 0,62 & 0,52 & 0,61 & 0,50 & 0,76 & 0,65 & 0,44 & 0,57 & 1,808 & \\
\hline 11 & Body heat protective underwear is important & $\dot{\bar{X}}$ & 4,76 & 4,56 & 4,72 & 4,65 & 4,70 & 4,50 & 4,64 & 4,74 & 4,66 & 770 & \\
\hline & & S & 0,52 & 0,71 & 0,64 & 0,61 & 0,54 & 0,74 & 0,50 & 0,45 & 0,65 & $0,1 / 9$ & \\
\hline & Coolir & $\dot{x}$ & 4,47 & 4,16 & $\overline{4,43}$ & 4,35 & 4,22 & 4,31 & 4,21 & 4,26 & 4,34 & 2019 & \\
\hline 4. 5 . & peopl & S & 0,76 & 0,95 & 0,79 & 0,93 & 0,95 & 0,79 & 1,05 & 0,86 & 0,85 & 2,049 & 0,012 \\
\hline 46 & $\overline{\text { Directi }}$ & $\dot{\bar{x}}$ & 3,98 & 3,68 & 3,99 & $\overline{3,88}$ & 3,90 & 3,42 & 3,64 & 4,29 & 3,80 & & \\
\hline 4. 6 . & & $S$ & 1,12 & 1,03 & 1,05 & 0,99 & 1,08 & 1,18 & 1,01 & 1,12 & \begin{tabular}{|l|}
1,08 \\
\end{tabular} & $1,49 /$ & \\
\hline & GPS p & $\dot{X}$ & 4,13 & 3,89 & 4,17 & 4,29 & 3,95 & 3,72 & 3,71 & 4,21 & 4,02 & & $05^{\circ}>$ \\
\hline 4. 7 . & & $S$ & 1,10 & 1,04 & 1,06 & 0,92 & 1,10 & 1,09 & 1,07 & 1,18 & 1,06 & 0,942 & 0,522 \\
\hline & ord nlaving T\&C nroducts are & $\dot{x}$ & 2,99 & 2,43 & 3,26 & 3,00 & 2,27 & 2,44 & 3,57 & 3,00 & 2,64 & & \\
\hline 8. & & $\mathrm{~S}$ & 1,33 & 1,42 & 1,39 & 1,22 & 1,26 & 1,38 & 1,09 & 1,38 & 1,40 & 2,599 & 0,001 \\
\hline & Body vital signal watching T\& C products are & $\dot{\bar{x}}$ & 4,10 & 3,97 & 4,36 & 4,41 & 3,78 & 3,72 & 3,64 & 4,04 & 4,07 & & \\
\hline & & S & 1,05 & 1,08 & 0,80 & 0,94 & 1,18 & 1,16 & 1,15 & 1,20 & 1,04 & & \\
\hline & & $\dot{X}$ & 3,41 & 3,29 & 3,62 & 3,06 & 3,16 & 3,36 & 3,36 & 3,70 & 3,32 & & \\
\hline & & & 1,35 & 1,24 & 1,36 & 1,03 & 1,29 & 1,22 & 1,08 & 1,22 & 1,32 & & \\
\hline
\end{tabular}

\section{Results and Discussion}

Functional and smart textile and clothing market is constantly growing with higher acceleration then the regular textile and clothing market. Technology levels of such products are giving promises to the consumer about more comfortable, more health caring, more safety, more reliability and wellness. Such special products are opening new markets for the aging population in the developed countries. Market penetration and commercialization ratio of such innovative special products are rising as result of gradual reduction of component costs, rising consumer interest and improving technologies.

Functional and smart textile products manufacturing enterprises are expected to respond to the voice of elder people market. Consumer desires and expectations in such dynamic market need to be covered immediately. Influential factors behind the purchasing behavior of such special consumer group needs to be defined, understand and responded clearly.

The results of the study have shown that there are differences between different gender, age and education level groups. When compared the approaches of female and male participants to the statements, consumers pay attention to the functional textile and clothing products. There are some gaps in the market both in supplier and consumer sides.

\section{Acknowledgement}

This study is part of a graduate thesis work, and authors are grateful to the Scientific Research Program of Pamukkale University for the financial support.

\section{References}

Url 1: "Percentage of the World Population Over 65 - 1950-2050" by Rcragun - Own work. Licensed under CC BY 3. 0 via Wikimedia Commons - http: //commons. wikimedia. org/wiki/File: Percentage_of_the_World_Population_Over_65_-_1950-2050. png\#media viewer/File: Percentage_of_the_World_Population_Over_65_-_1950-2050. png, access date : $26 . \overline{02} . \overline{2015}$ 
Richards, M. L. (1981),The Clothing Preferences and Problems of Elderly Female Consumers, The Gerontologist (1981) 21 (3): $263-267$. Jackson, H. O. (1992), Aging and Expenditures on Apparel, Clothing and Textiles Research Journal January, vol. 10 no. 2 24-28

Shim, S. , Bickle, M. C. (1993), Women 55 Years and Older as Catalog Shoppers: Satisfaction with Apparel Fit and Catalog Attributes, Clothing and Textiles Research Journal June, vol. 11 no. 4 53-64

Goldsberry, E. , Shim S. , and Naomi Reich, N. (1996), Women 55 Years and Older: Part I Current Body Measurements As Contrasted to the PS 42-70 Data, Clothing and Textiles Research Journal March, vol. 14 no. 2 108-120

Goldsberry, E. , Shim S. , and Naomi Reich, N. (1996), Women 55 Years and Older: Part II. Overall Satisfaction and Dissatisfaction with the Fit of Ready-to-Wear, Clothing and Textiles Research Journal March, vol. 14 no. 2 121-132

Vural, T. , Çileroğlu, B. , Çoruh, E. (2008), Body size standardization in terms of underwear production of women of 60 years and above, Tekstil ve Konfeksiyon, 2/2008

Harriet Meinander H. , Varheenmaa, M. , Clothing and textiles for disabled and elderly people, VTT TIEDOTTEITA - Research Notes 2143, ISBN 951-38-5897-9

Civitci Sule, (2004), An ergonomic garment design for elderly Turkish men, Applied Ergonomics, Volume 35, Issue 3, May, Pages 243251

Joung, H. , Miller, N. J. , (2006),"Factors of dress affecting self-esteem in older females", Journal of Fashion Marketing and Management: An International Journal, Vol. 10 Iss 4 pp. 466 - 478

Pisut, G. , \& Connell, L. J. (2007). Fit preferences of female consumers in the USA. Journal of Fashion Marketing and Management, 11 , 366-379.

Mak Man Nga, M. (2011), Study and design of elderly aesthetic apparel", in Bachelor of Arts (Honors) In Fashion \& Textiles program in Institute of Textiles \& Clothing the Hong Kong Polytechnic University

Chattaraman, V. , Simmons K. P. , and Ulrich, P. V. (2013) Age, Body Size, Body Image, and Fit Preferences of Male Consumers, Clothing and Textiles Research Journal 31 (4) 291-305

Twigg, J. , Majima, S. , (2014) Consumption and the constitution of age: Expenditure patterns on clothing, hair and cosmetics among post-war 'baby boomers, Journal of Aging Studies 30 (2014) 23-32

Lam Po S. , Tang L. P. , G. K. Stylios, (2006),"An overview of smart technologies for clothing design and engineering", International Journal of Clothing Science and Technology, Vol. 18 Iss 2 pp. 108 - 128

Tao, X. (2001), Smart Fibers, Fabrics and Clothing, CRC Woodhead Publishing Ltd, Cambridge. 